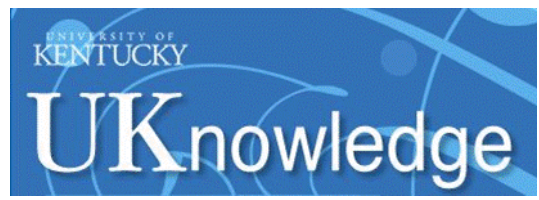

University of Kentucky

UKnowledge

Institute for Pharmaceutical Outcomes and

Policy Faculty Publications

Pharmaceutical Outcomes and Policy

$1-2017$

\title{
Utilization of Free Medication Samples in the United States in a Nationally Representative Sample: 2009-2013
}

\author{
Joshua D. Brown \\ University of Kentucky, josh.brown@uky.edu \\ Pratik A. Doshi \\ University of Kentucky, pratik.doshi@uky.edu \\ Jeffery C. Talbert \\ University of Kentucky, jeff.talbert@uky.edu
}

Follow this and additional works at: https://uknowledge.uky.edu/ipop_facpub

Part of the Pharmacy Administration, Policy and Regulation Commons

Right click to open a feedback form in a new tab to let us know how this document benefits you.

\section{Repository Citation}

Brown, Joshua D.; Doshi, Pratik A.; and Talbert, Jeffery C., "Utilization of Free Medication Samples in the United States in a Nationally Representative Sample: 2009-2013" (2017). Institute for Pharmaceutical Outcomes and Policy Faculty Publications. 2.

https://uknowledge.uky.edu/ipop_facpub/2

This Article is brought to you for free and open access by the Pharmaceutical Outcomes and Policy at UKnowledge. It has been accepted for inclusion in Institute for Pharmaceutical Outcomes and Policy Faculty Publications by an authorized administrator of UKnowledge. For more information, please contact UKnowledge@lsv.uky.edu. 
Utilization of Free Medication Samples in the United States in a Nationally Representative Sample: 2009-2013

Digital Object Identifier (DOI)

https://doi.org/10.1016/j.sapharm.2016.01.006

Notes/Citation Information

Published in Research in Social and Administrative Pharmacy, v. 13, issue 1, p. 193-200.

(c) 2016 Elsevier Inc. All rights reserved.

This manuscript version is made available under the CC-BY-NC-ND 4.0 license

https://creativecommons.org/licenses/by-nc-nd/4.0/.

The document available for download is the author's post-peer-review final draft of the article. 


\title{
Utilization of free medication samples in the United States in a nationally representative sample: 2009-2013
}

\author{
Joshua D. Brown, Pharm.D., M.S. ${ }^{*}$ Pratik A. Doshi, M.S., and Jeffery C. Talbert, Ph.D. \\ Institute for Pharmaceutical Outcomes \& Policy, Department of Pharmacy Practice \& Science, \\ University of Kentucky College of Pharmacy, 789 S. Limestone St \#292E, Lexington, KY, USA
}

\begin{abstract}
Background-Manufacturers provide free sample medications as a means to increase use of branded medications. Sample use varies year-to-year as branded product patents expire and new products come to market.
\end{abstract}

Objective-This study sought to describe the use of sample medications during 2009-2013 and assess individual characteristics associated with sample use.

Methods-Data from the 2009-2013 U.S. Medical Expenditure Panel Survey (MEPS) were used. MEPS asks participants whether they received each medication they are taking as a sample. The top 10 medications and medication classes used each year by volume were identified as well as the proportion of people who used at least one sample medication. The proportion of new initiators of medications were also classified as the percent who received a sample for the specific medication. Logistic regression was used to assess individual demographics, insurance, and medication characteristics associated with use.

Results-Prevalence of sample use ranged from $9.3 \%$ in 2009 to $6.2 \%$ in 2013 . The most widely used sample medications included statins during 2009-2011, which changed to inhaled $\beta$-agonists in 2012-2013, as atorvastatin became available as a generic. The overall volume of the top 10 free sample medications decreased by one-third over this study period. In 2013, 12.6\% of new insulin analog users and $11.0 \%$ of new oral contraceptive users receive these medications through samples. Regression analysis showed that U.S. Medicaid- and Medicare-insured persons were less likely to use samples compared to those with private insurance.

Conclusions-Sample medication use has decreased as generic medications are becoming more used in the U.S.

\section{Keywords}

Sample medications; Generic drugs; Pharmaceutical marketing; Physician prescribing

\footnotetext{
*Corresponding author. Tel.: +1 479650 8047; fax: +1 859323 0069. josh.brown@uky.edu (J.D. Brown). Conflicts of interest: None.
} 


\section{Introduction}

Free medication samples are widely disbursed to prescribers as a marketing tool for trade name products. In 2005 , the total value of medications provided was approximately $\$ 18$ billion, with up to $20 \%$ of all Americans and nearly 50\% of Medicare beneficiaries utilizing samples annually. ${ }^{1,2}$ This practice is seen as pervasive by some medical associations and patient advocacy groups but is typically viewed positively by prescribers and patients. ${ }^{3,4}$ As implied, patients receive the medications for free and avoid immediate costs of the medication at the point of care. Therapy is initiated immediately without a pharmacy visit and the prescriber has the opportunity to provide medication counseling, which can be important for certain dosage forms or devices. ${ }^{5}$

Despite the perceived benefits, pharmaceutical companies intend the practice as a means to increase use of branded medications. This can lead to increased use of more expensive branded products, which increases costs to both patients and third-party payers if the sampled medication is continued versus a suitable generic alternative. ${ }^{6-9}$ Further, use of sample medications forgoes the typical process of prescribing and dispensing and removes the medication experts - pharmacists - from their roles in screening for potential drug- drug and drug-disease interactions and in providing medication counseling. ${ }^{10}$

Medication sample use is difficult to analyze as the practice circumvents the process of recording filled medications at the pharmacy or in insurance billing claims. Previous studies have utilized the U.S. Medical Expenditure Panel Survey (MEPS) to investigate sample use given that it provides a self-reported estimate of sample use in a nationally representative weighted sample. ${ }^{11,12}$ These studies have looked at medication use through 2005 and have identified individual characteristics associated with sample medication use. Medication samples and the individuals utilizing them will vary by time as medication patent life expires and because generic medication use has become more prevalent over the last decade. Thus, this study sought to update the information regarding sample medication use in the U.S. during the most recent five-year period available in MEPS (2009-2013). Medications used as samples were identified and the individual characteristics associated with sample use in the most recent year (2013) were also explored.

\section{Methods}

Data sources

MEPS data were used to estimate the scope of free sample use and to characterize the typical user. MEPS data are de-identified and publicly available and contain information on patient demographics, sources of payment, medical service and pharmaceutical medication utilization and expenditures. Due to the public and de-identified nature of these data, they are exempt from an institutional review board approval process.

\section{Study population and design}

Data from years 2009-2013 were used to conduct a cross-sectional study that looked at the disbursement of free medication samples in the U.S. over this time period. The most recent 
year available, 2013, was used to evaluate the individual characteristics of sample users. There were no exclusions applied to the study sample.

\section{Sample prescription medication use}

MEPS provided "Prescribed Medicines" files that contain information on prescription medication use. Survey respondents are first asked about the medications they use and if they received any of these medications as free samples. Any patient that identified at least one of their medications as a free sample was considered a sample user for the study. Patients are also asked to identify if they are a new user of a particular medication for the respective year. The "Prescribed Medicines" file includes medication information for each person and Generic Product Identifier (GPI) codes (Medi-Span, Indianapolis, IN) were used to identify medications including all formulations for each medication. Using weights from expenditure files provided by MEPS, the top 10 classes of medications and top 10 medications for each year of the data from 2009 to 2013 by volume were determined as well as the percent of the population using sample medications each year. Additionally, for new users of any medications in each year, the percent of patients receiving free sample for that particular medication in the given year was reported.

\section{Sample users characteristics in 2013}

MEPS 2013 "Full Year Consolidated" files contained demographic information on the respondents. Race and ethnicity were combined into a single variable with the following categories: Hispanics, non-Hispanic Whites, non-Hispanic Blacks and non-Hispanics that belonged to other races. A new medical insurance indicator was created from variables available in the data, and it consisted of the following insurance provider categories: Private, Medicaid, Medicare (dual eligibles were classified in the Medicaid group), other public insurance, and uninsured. Additionally, an indicator for prescription medication insurance was included. Educational status was collapsed into two levels: lower than high school, and at least high school level. Family income, as a percentage of the annual Federal Poverty Limit (FPL), was classified for income $<100 \%$ of FPL, $\geq 100$ and $<125 \%$ of FPL, $\geq 125 \%$ and $<200 \%$ of FPL, $\geq 200 \%$ and $<400 \%$ of FPL, $\geq 400 \%$ of FPL. Geographic region was based on U.S. Census regions. The total number of prescription medications used by each individual in 2013 was also calculated.

\section{Statistical analyses}

All statistical analyses were conducted using SAS 9.4 (Cary, North Carolina). SAS survey commands were utilized to incorporate survey weights provided by MEPS; this allows the generalization of results to represent the national population based on race, gender, age, and geographic factors. Weighted counts and frequencies are reported for patient characteristics for the year 2013. Chi-square tests were used to compare across categorical variables. A multiple logistic regression model was performed to identify factors associated with the receipt of any sample medications for 2013. This model included patient demographics, access to care variables, and the count of total prescription medications. Odds ratios and 95\% CI are reported. The significance level for the study was set at $a<0.05$. 


\section{Results}

\section{Medications used as samples}

Over the time period 2009-2013, prevalence of sample medication use decreased in the U.S. from $9.3 \%$ in 2009 to $6.2 \%$ in 2013 . Table 1 shows the top 10 individual medications and medication classes used as samples by volume. During 2009-2011, HMG Co-A reductase inhibitors ("statins") were the most widely used sample medications, with a volume of roughly 1.3 million samples each year. This group consisted mostly of rosuvastatin and atorvastatin. Statins were supplanted by inhaled $\beta$-agonists, as atorvastatin lost patent protection heading into 2012. Some medications widely available as generics but with branded versions were in the top 10 in 2013, such as levothyroxine. Other highly used free sample medication classes in 2013 included non-steroid anti-inflammatory drugs (NSAIDs), proton pump inhibitors (PPIs), insulin analogs, and oral contraceptives. The total volume of samples utilized in the top 10 medication classes decreased by over one-third between 2009 and 2013 (9 million to 6 million). For those under 18 years of age, asthma medications were the highest utilized classes. For non-elderly adults, more variation was present with inhaled $\beta$-agonists, anti-depressants, and statins being highly used, among others. For elderly individuals, inhaled $\beta$-agonists ( \pm steroids), statins, and $\beta$-blockers (oral and ophthalmic) were highly utilized.

Table 2 shows the percent of people who were new initiators of each medication class who used a sample for that class. For example, in $2009,5.2 \%$ of statin initiators used a statin sample while in 2013 only $2.8 \%$ did. In 2013, the highest initiators using samples were among insulin users (12.6\%), selective norepinephrine reuptake inhibitors (SNRIs; 13.9\%), and oral contraceptives $(11.0 \%)$.

\section{Characteristics of free sample users}

Characteristics of samples users and non-users in 2013 are summarized in Table 3. The total weighted sample represented nearly 180 million people in the U.S. who filled a prescription medication. Table 4 shows the adjusted comparisons of users and non-users with adjusted odds ratios (aOR) and 95\% confidence intervals (CI). Gender, age, race, prescription drug coverage, family income, and region were all non-significant predictors of sample use. Those with Medicaid $(\mathrm{aOR}=0.63,95 \%$ CI $0.43-0.92)$ or Medicare $(\mathrm{aOR}=0.56,95 \%$ CI 0.34-0.95) insurance were less likely to use samples compared to those with private insurance. Other public insurance and uninsured status was not associated with sample use compared to the 'Private' reference group. Those with high school or higher education had 17-98\% higher odds of being sample users compared to those with less than a high school education. Also, for each additional prescription medication filled, the odds of sample used increased by roughly $1-2 \%$. The c-statistic for the model was 0.649 , showing low model discriminatory power for sample users.

\section{Discussion}

Year-to-year variability was observed in the medications sampled, which is associated with patent expiry and new medications coming onto the market throughout the time period. 
Thus, the characteristics of free sample users are likely to change as new disease states are treated by these sampled medications. Also observed was an overall decrease in sample use as measured by the prevalence of sample users as well as the total volume of sample use. This is attributed to the increase in generic utilization ( $85 \%$ of all prescriptions by volume) overall in the U.S. as the number of block-bluster branded products have decreased. ${ }^{13}$ Despite decreasing prevalence, sample medications have a tremendous economic impact ${ }^{7}, 14$ and can also influence research on products available through samples. ${ }^{15}$

Sample medications are provided as a means of pharmaceutical marketing of branded products, even when direct (i.e. same chemical entity) or therapeutic (i.e. same therapeutic class) substitutes exist. ${ }^{7}$ While the practice has been defended as a means to provide medications to those without insurance,,${ }^{16}$ this does not appear to be the case in this study or in previous literature, ${ }^{11,12}$ and is counterintuitive, as uninsured individuals have fewer means to attain branded products once the sample supply is extinguished. Cost implications associated with this practice can impact individual out-of-pocket spending as well as thirdparty payer costs. This is especially concerning when low-cost generic programs are widely prevalent and provide access to affordable medications regardless of insurance. ${ }^{17,18}$

A study by Duru et al investigated the potential cost savings associated with both direct and therapeutic substitution among diabetic patients with Medicare Part D coverage. ${ }^{7}$ They found that direct substitution would save approximately $\$ 150$ dollars per person and therapeutic substitution would save $\$ 400$ per person. Among the top ten medications in 2013, only levothyroxine was available as a generic. However, this is also an example where substitution may not necessarily confer equivalence, as levothyroxine products have been shown to vary in their bioavailability. ${ }^{19,20}$ Other examples include warfarin, estrogens, and anticonvulants, which were also in the top 20 of all free sample drugs (data not shown). ${ }^{21}$ This further highlights the marketing strategy of free sample medications, as a patient could not necessarily move from the sample branded product to a generic version without a potential dose adjustment. Therapeutic substitution implies equivalence within a class, which is arguable for a number of the Top 10 sampled classes including statins, NSAIDs, PPIs, and SNRIs. ${ }^{22}$

\section{Limitations}

This study is subject to some limitations. Primarily, sample use is self-reported by MEPS participants who could misunderstand the question or have recall bias, although participants are led through the survey by trained personnel. Other important medications by expenditures, such as self-injected biologics, were also observed but not reportable due to low sample sizes. The a priori objectives of this study were also to investigate individual access to care characteristics as well as provider characteristics that were may be predictive of sample use. However, a high number of missing responses were observed, limiting the usefulness of these variables. Further, the adjusted model showed low discriminatory power for sample users. This suggests that other individual characteristics, or prescriber characteristics, may be predictive of sample use other than those variables included here. 


\section{Conclusion}

In the United States, $6.2 \%$ of prescription medication users used a free sample medication. The types of medications used as samples changes annually as medications patent life expires or new medications enter the market. Sample medications have tremendous cost implications, especially when direct or therapeutic generic substitutes exist.

\section{Acknowledgments}

Funding source: None.

\section{References}

1. Donohue JM, Cevasco M, Rosenthal MB. A decade of direct-to-consumer advertising of prescription drugs. N Engl J Med. 2007; 357:673-681. [PubMed: 17699817]

2. Tjia J, Briesacher BA, Soumerai SB, et al. Medicare beneficiaries and free prescription drug samples: a national survey. J Gen Intern Med. 2008; 23:709-714. [PubMed: 18365289]

3. Chew LD, O'Young TS, Hazlet TK, Bradley KA, Maynard C, Lessler DS. A physician survey of the effect of drug sample availability on physicians' behavior. J Gen Int Med. 2000; 15:478-483.

4. Gibbons RV, Landry FJ, Blouch DL, et al. A comparison of physicians' and patients' attitudes toward pharmaceutical industry gifts. J Gen Int Med. 1998; 13:151-154.

5. Gellad WF, Huskamp HA, Li A, Zhang Y, Safran DG, Donohue JM. Use of prescription drug samples and patient assistance programs, and the role of doctor-patient communication. J Gen Int Med. 2011; 26:1458-1464.

6. Lahey T. The high costs of "free" drug samples. Clin Transl Gastroenterol. 2014; 5:e67. http:// dx.doi.org/10.1038/ctg.2014.16. [PubMed: 25521040]

7. Duru OK, Ettner SL, Turk N, et al. Potential savings associated with drug substitution in Medicare part D: the translating research into action for diabetes (TRIAD) study. J Gen Intern Med. 2014; 29:230-236. [PubMed: 23975059]

8. Evans KL, Brown SR, Smetana GW. Sample closet medications are neither novel nor useful. J Am Board Fam Med. 2013; 26:380-387. [PubMed: 23833152]

9. Pinckney RG, Helminski AS, Kennedy AG, Maclean CD, Hurowitz L, Cote E. The effect of medication samples on self-reported prescribing practices: a statewide, cross-sectional survey. J Gen Int Med. 2011; 26:40-44.

10. Mott DA, Cline RR. Exploring generic drug use behavior: the role of prescribers and pharmacists in the opportunity for generic drug use and generic substitution. Med Care. 2002; 40:662-674. [PubMed: 12187180]

11. Cutrona SL, Woolhandler S, Lasser KE, Bor DH, McCormick D, Himmelstein DU. Characteristics of recipients of free prescription drug samples: a nationally representative analysis. Am J Public Health. 2008; 98:284. [PubMed: 18172135]

12. Macdougall C, Udkow T, Guglielmo BJ, Vittinghoff E, Martin J. National estimates and predictors of prescription medication sample use in the United States, 1999-2005. J Am Pharm Assoc. 2003; 2010(50):677-685.

13. IMS Institute for Healthcare Informatics. The Use of Medicines in the United States: Review of 2011. 2012

14. Haas JS, Phillips KA, Gerstenberger EP, Seger AC. Potential savings from substituting generic drugs for brand-name drugs: medical expenditure panel survey, 1997-2000. Ann Intern Med. 2005; 142(11):891-897. 142/11/891 [pii]. [PubMed: 15941695]

15. Li, X., Sturmer, T., Brookhart, MA. Evidence of sample use among new users of statins: Implications for pharmacoepidemiology. Med Care. 2014. http://dx.doi.org/10.1097/MLR. 0000000000000174

16. Johnson, K. Drug Samples to Doctors. New York Times; Feb 9. 2006 p. A26 
17. Pauly NJ, Talbert JC, Brown JD. The prevalence and predictors of low-cost generic program use in the pediatric population. Drugs Real World Outcomes. 2015; 2:411-419. [PubMed: 26690285]

18. Pauly NJ, Brown JD. Prevalence of low-cost generic program use in a nationally representative cohort of privately insured adults. J Manag Care Spec Pharm. 2015; 21(12):1162-1170. 2015(21)12: 1162-1170 [pii]. [PubMed: 26679965]

19. Phillips CJ. A health economic perspective on generic therapeutic substitution. Eur J Hosp Pharm Sci Pract. 2013; 20:290-292.

20. Gothe H, Schall I, Saverno K, et al. The impact of generic substitution on health and economic outcomes: a systematic review. Appl Health Econ Health Policy. 2015; 13(suppl 1):S21-S33. http://dx.doi.org/10.1007/s40258-014-0147-0. [PubMed: 26091709]

21. Paveliu MS, Bengea S, Paveliu FS. Generic substitution issues: brand-generic substitution, genericgeneric substitution, and generic substitution of narrow therapeutic index (NTI)/critical dose drugs. Maedica. 2011; 6:52. [PubMed: 21977191]

22. Kesselheim AS, Misono AS, Lee JL, et al. Clinical equivalence of generic and brand-name drugs used in cardiovascular disease: a systematic review and meta-analysis. JAMA. 2008; 300:25142526. [PubMed: 19050195] 


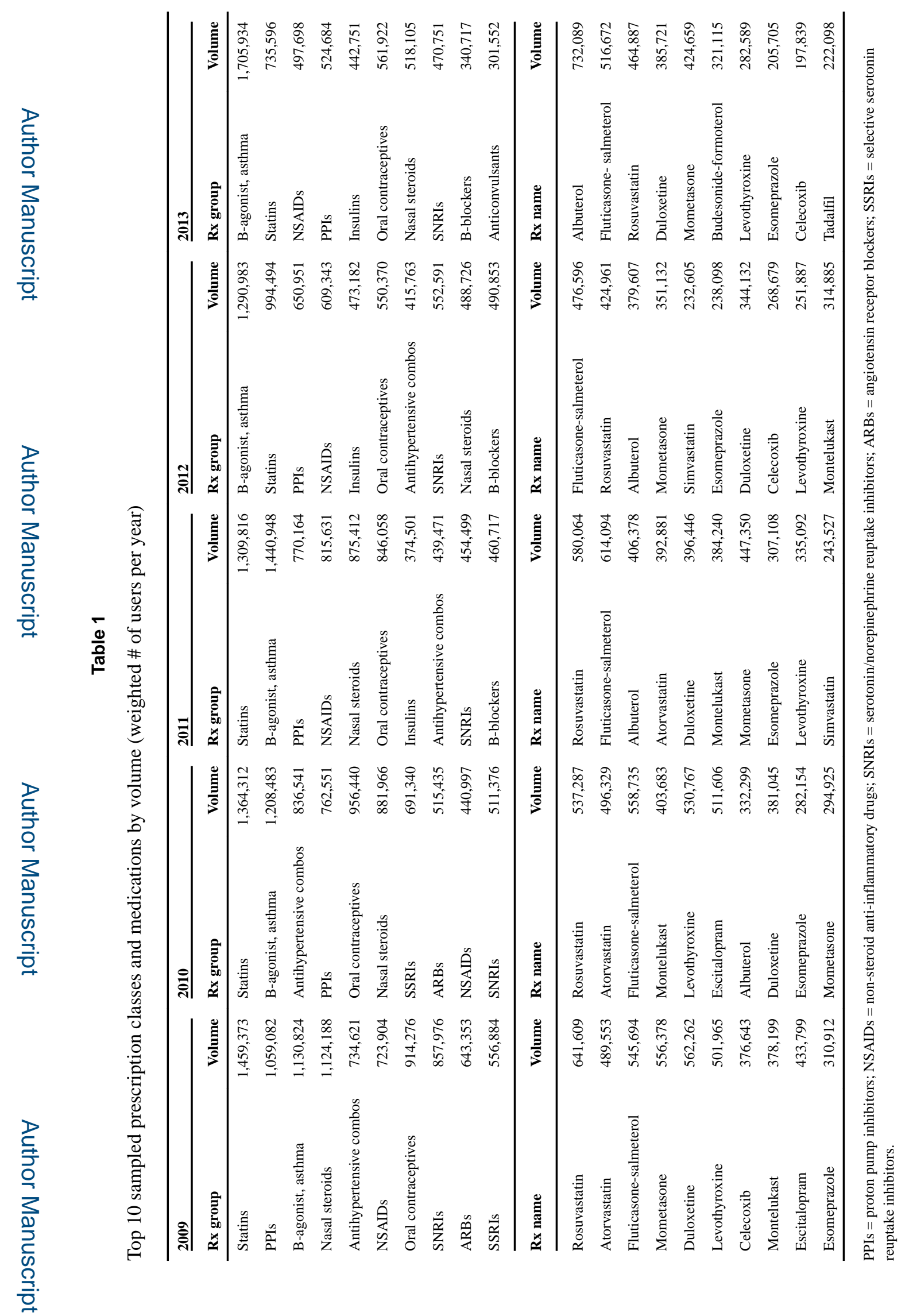

Res Social Adm Pharm. Author manuscript; available in PMC 2017 December 20. 

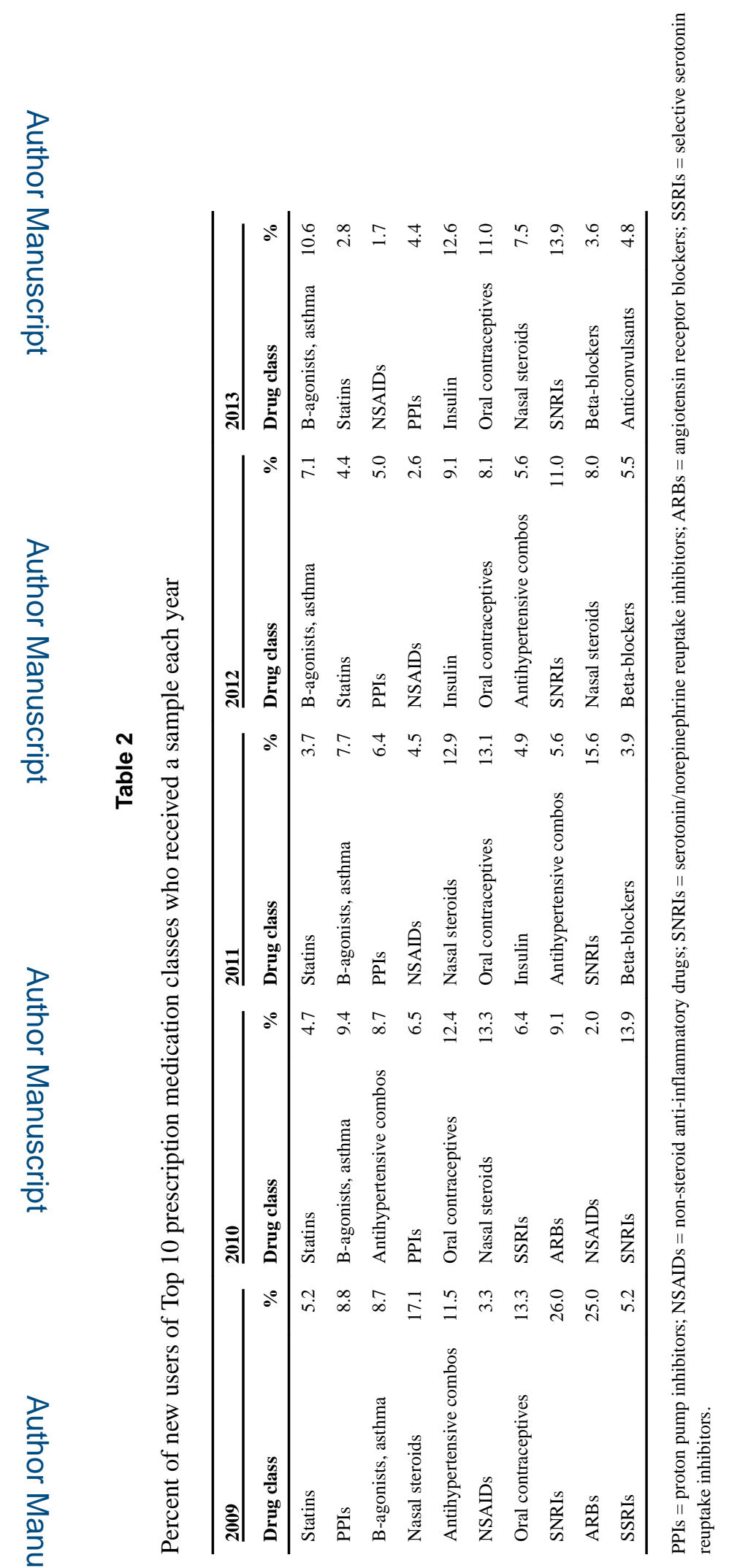


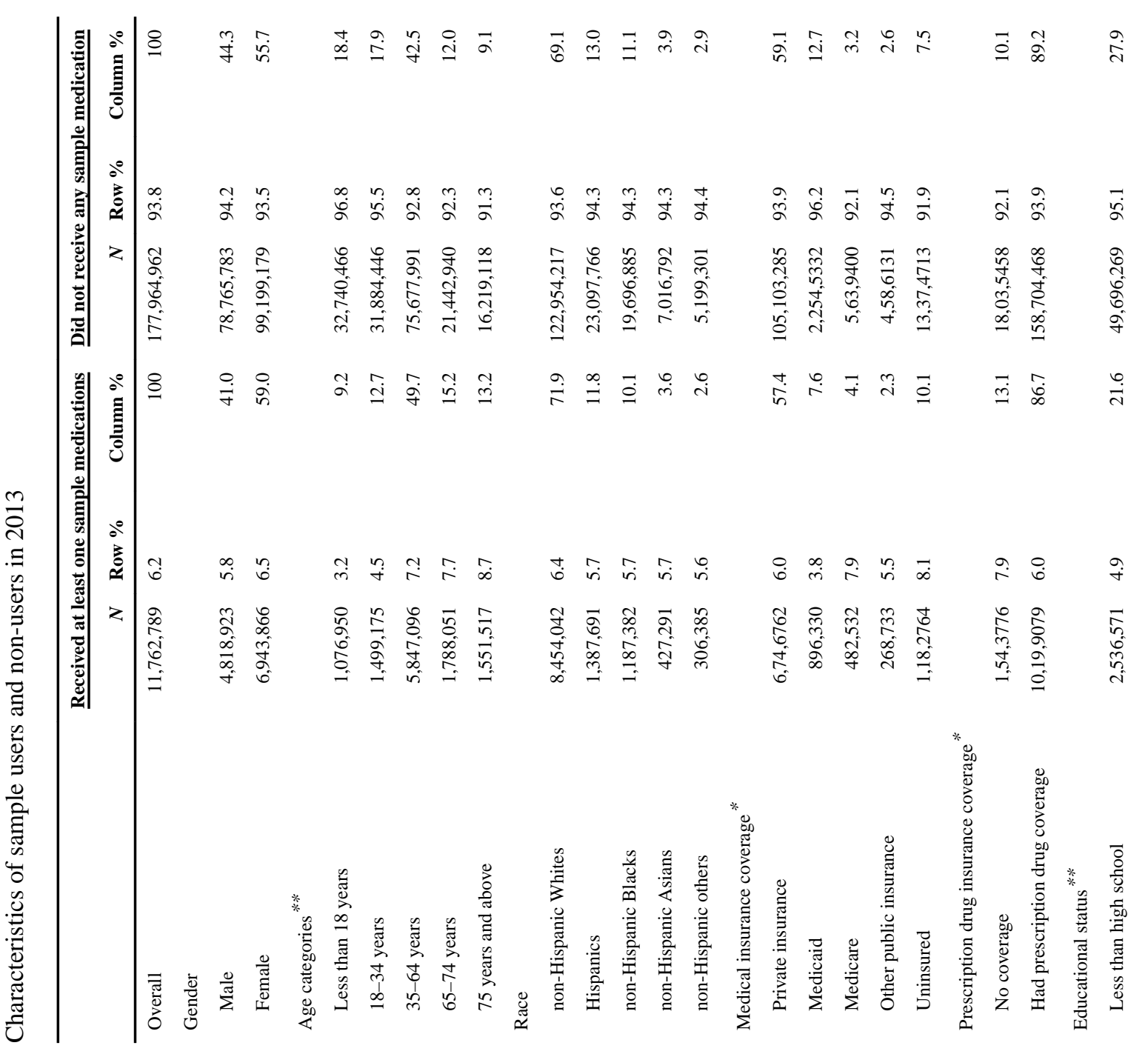




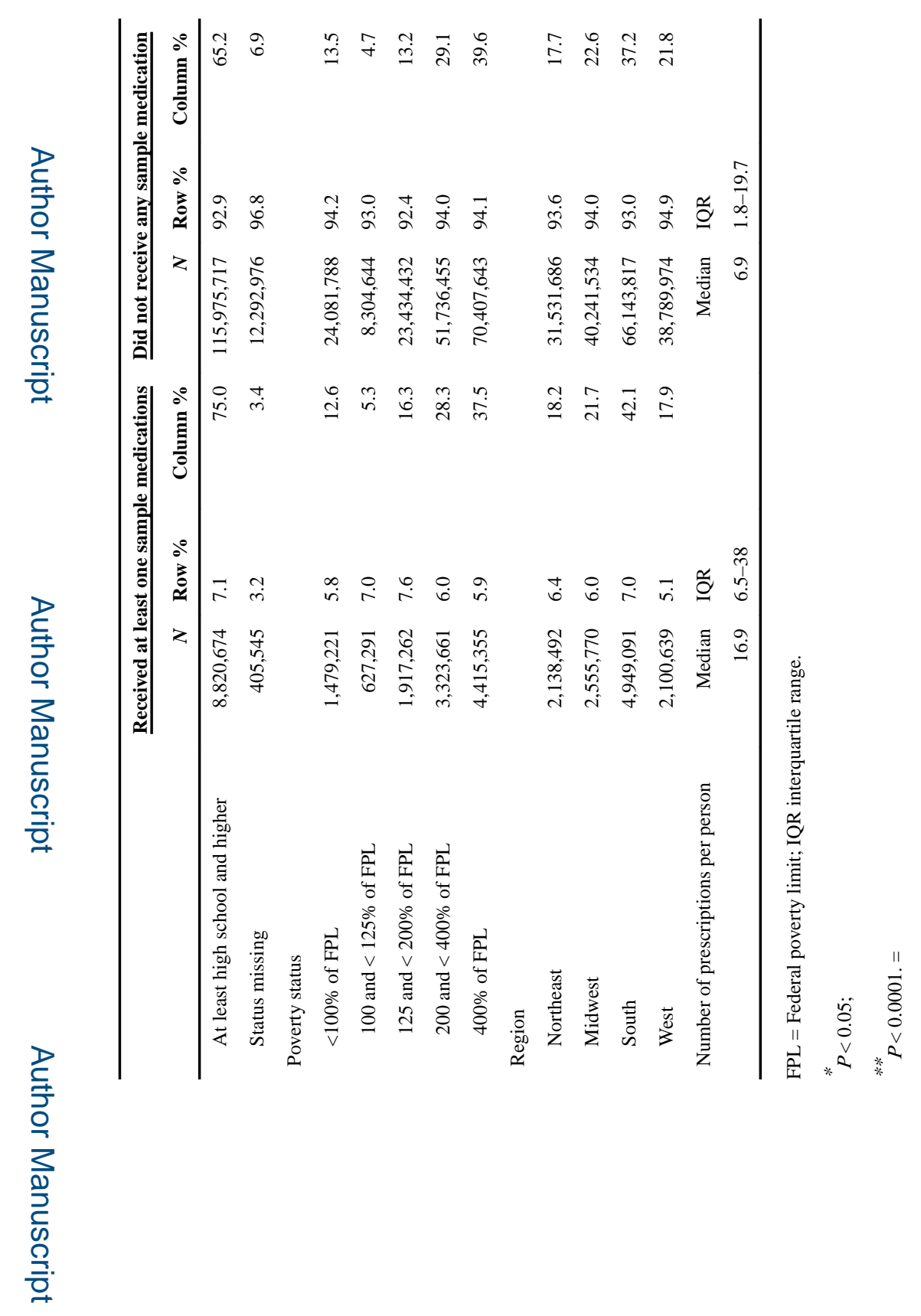

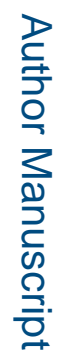


Table 4

Results of multiple logistic regression predicting use of sample medications in 2013

\begin{tabular}{|c|c|c|c|}
\hline & Adjusted odds ratio & $95 \% \mathrm{CI}$ & $P$-value \\
\hline \multicolumn{4}{|l|}{ Gender } \\
\hline Male & Ref. & Ref. & Ref. \\
\hline Female & 1.14 & $0.96,1.36$ & 0.1481 \\
\hline \multicolumn{4}{|l|}{ Age categories } \\
\hline Less than 18 years & Ref. & Ref. & Ref. \\
\hline $18-34$ years & 0.81 & $0.50,1.30$ & 0.3835 \\
\hline $35-64$ years & 1.10 & $0.73,1.68$ & 0.6453 \\
\hline $65-74$ years & 1.16 & $0.72,1.87$ & 0.5504 \\
\hline 75 years and above & 1.27 & $0.73,2.22$ & 0.3918 \\
\hline \multicolumn{4}{|l|}{ Race } \\
\hline non-Hispanic Whites & Ref. & Ref. & Ref. \\
\hline Hispanics & 1.19 & $0.94,1.51$ & 0.1428 \\
\hline non-Hispanic Blacks & 0.89 & $0.73,1.10$ & 0.2958 \\
\hline Asians & 1.15 & $0.77,1.72$ & 0.4864 \\
\hline Others & 0.92 & $0.53,1.58$ & 0.7527 \\
\hline \multicolumn{4}{|l|}{ Medical insurance coverage } \\
\hline Private insurance & Ref. & Ref. & Ref. \\
\hline Medicaid & 0.63 & $0.43,0.92$ & 0.0155 \\
\hline Medicare & 0.56 & $0.34,0.95$ & 0.0303 \\
\hline Other public insurance & 0.88 & $0.52,1.49$ & 0.6205 \\
\hline Uninsured & 1.19 & $0.80,1.77$ & 0.3909 \\
\hline \multicolumn{4}{|l|}{ Prescription drug insurance coverage } \\
\hline No & Ref. & Ref. & Ref. \\
\hline Yes & 0.74 & $0.52,1.03$ & 0.0759 \\
\hline \multicolumn{4}{|l|}{ Educational status } \\
\hline Less than high school & Ref. & Ref. & Ref. \\
\hline At least high school and higher & 1.52 & $1.17,1.98$ & 0.0021 \\
\hline Status missing & 1.03 & $0.62,1.72$ & 0.9089 \\
\hline \multicolumn{4}{|l|}{ Poverty status (family income) } \\
\hline$<100 \%$ of FPL & Ref. & Ref. & Ref. \\
\hline$\geq 100$ and $<125 \%$ of FPL & 1.00 & $0.68,1.47$ & 0.9876 \\
\hline$\geq 125$ and $<200 \%$ of FPL & 1.07 & $0.74,1.55$ & 0.7291 \\
\hline$\geq 200$ and $<400 \%$ of FPL & 0.81 & $0.56,1.17$ & 0.2656 \\
\hline$\geq 400 \%$ of FPL & 0.83 & $0.58,1.17$ & 0.2847 \\
\hline \multicolumn{4}{|l|}{ Region } \\
\hline Northeast & Ref. & Ref. & Ref. \\
\hline Midwest & 0.98 & $0.69,1.41$ & 0.9261 \\
\hline South & 1.18 & $0.87,1.62$ & 0.2898 \\
\hline West & 0.82 & $0.58,1.18$ & 0.2873 \\
\hline
\end{tabular}




\begin{tabular}{llll}
\hline & Adjusted odds ratio & $\mathbf{9 5 \%}$ CI & $\boldsymbol{P}$-value \\
\hline Number of prescriptions & 1.02 & $1.01,1.02$ & $<0.0001$ \\
\hline
\end{tabular}

$\mathrm{FPL}=$ federal poverty limit; $\mathrm{CI}=$ confidence interval. 